\title{
Synthesis of Propylene Oxide - Styrene Copolymers
}

\author{
Mohamed Benadda ${ }^{1,}$, , Mohammed Issam Ferrahi ${ }^{1}$, Rachid Meghabar ${ }^{1}$ \\ 1 Laboratory of Polymer Chemistry, Department of Chemistry, Faculty of Sciences, Université Ahmed Benbella, BP 1524. \\ El M'nouar, 31000 Oran, Algeria \\ Correspondence: benadda_mohammed@yahoo.fr;
}

Scopus Author ID 55059521200

Received: 8.11.2020; Revised: 5.01.2021; Accepted: 8.01.2021; Published: 19.01.2021

\begin{abstract}
The copolymerization of propylene oxide (PO) with styrene (St) catalyzed by Maghnite- $\mathrm{H}^{+}$ $\left(\mathrm{Mag}-\mathrm{H}^{+}\right)$was investigated. Mag- $\mathrm{H}^{+}$, a nontoxic catalyst for cationic polymerization of vinylic and heterocyclic monomers, is a montmorillonite silicate sheet clay. This catalyst was prepared through a straight forward proton exchange process. It was found that Mag-H+ initiates the copolymerization in bulk at room temperature. Various techniques, including $\mathrm{H}^{1} \mathrm{NMR},{ }^{13} \mathrm{C}-\mathrm{NMR}$, FT-IR spectroscopy, and Ubbelohde viscometer, were used to elucidate the resulting copolymers' structural characteristics. The effects of the amount of Mag- $\mathrm{H}^{+}$and propylene oxide were studied. The yield of copolymerization depends on the amount of Mag- $\mathrm{H}^{+}$used and the reaction time.
\end{abstract}

Keywords: Maghnite- $\mathrm{H}^{+}$; propylene oxide; styrene; montmorillonite; copolymerization.

(C) 2020 by the authors. This article is an open-access article distributed under the terms and conditions of the Creative Commons Attribution (CC BY) license (https://creativecommons.org/licenses/by/4.0/).

\section{Introduction}

Copolymerization is one of the important techniques adopted in effecting systematic changes in commercially important polymers' properties. Polyether elastomers are used in automotive and industrial applications that require materials with low gas permeability, retention of flexibility at both low and high temperatures, and stability upon extended exposure to heat, hydrocarbons, and ozone [1]. A variety of reagents will catalyze the ring-opening oligomerization or polymerization of epoxides [2], including metal alkoxides [3], and neutral and cationic aluminum complexes supported by chelating ligands such as porphyrins [4], hydrolyzed zinc, and cadmium alkyls [5], diamido amines [6], calcium amide-alkoxides [7]. The preparation of graft copolymers by use of macromonomers has been extensively investigated. This method provides an excellent means of designing graft copolymers of controlled structure [8-11]. Poly (propylene oxide) methacrylate, poly(ethylene oxide) methacrylate, and poly(propylene oxide-b-ethylene oxide) methacrylate were used to prepare graft copolymers by reaction with methyl methacrylate. These syntheses were reported previously $[12,13]$. Styrene has been copolymerized with various types of macromonomers [14-17]. Styrene's reaction with the poly (ethylene oxide) methacrylate is a useful preparative method for an amphiphilic graft copolymer [18]. Recently, H. T. Cunha et al. synthesize copolymer from the reaction of styrene with poly (propylene oxide) methacrylate observe the effect of the zinc chloride on incorporating the macro-monomer in the copolymer [19]. Many of these catalysts' inconveniences include high cost, poor polymerization activity, and generally, they are toxic. Montmorillonite, a class of inexpensive and non-corrosive solid acids, have been used as the reactions catalyzed by montmorillonites are usually carried out under 
mild conditions with high yields and high selectivities, and workup of these reactions is very simple. The only filtration to remove the catalyst and evaporation of the solvent are required. Montmorillonite catalysts are easily recovered and reused [20]. $\mathrm{Mag}-\mathrm{H}^{+}$is a green catalyst; it was successfully used in the cationic polymerization of vinyl monomers and heterocyclic monomers [21-33]. In this article, propylene oxide (PO) was selected for ring-opening copolymerization with styrene $(\mathrm{St})$, using Maghnite- $\mathrm{H}^{+}$as a catalyst.

\section{Materials and Methods}

\subsection{Materials.}

Maghnite- $\mathrm{H}^{+}$was prepared according to the process similar to that described by Belbachir et al. [33]. Raw-Maghnite (20 g) was crushed for 20 minutes using a pro labor ceramic balls grinder. It was then dried for 2 hours at $105^{\circ} \mathrm{C}$. The Maghnite was placed in an Erlenmeyer flask together with $500 \mathrm{ml}$ of distilled water. The Maghnite/water mixture was stirred using a magnetic stirrer and combined with $0.25 \mathrm{M}$ sulfuric acid solution until saturation was achieved over 2 days at room temperature; the mineral was then washed with distilled water to become sulfate-free and then dried at $105{ }^{\circ} \mathrm{C}$. Propylene oxide (PO 99\%), ethanol (99\%) were used as received. Styrene was purified by stirring over $\mathrm{CaH}_{2}$ for about $24 \mathrm{~h}$ and then distilled under reduced pressure over $\mathrm{CaH}_{2}$ and was finally stored under nitrogen atmosphere.

\subsection{Procedure and polymer characterization.}

The catalyst was dried in a muffle at $120^{\circ} \mathrm{C}$ overnight and then transferred to a vacuum desiccator containing $\mathrm{P}_{2} \mathrm{O}_{5}$. After cooling to room temperature under vacuum, the mineral was added to the Propylene oxide $4.82 \mathrm{~g}(0,083 \mathrm{~mol})$. Styrene $8.64 \mathrm{~g}(0,083 \mathrm{~mol})$ mixture was preliminarily kept in a stirred flask. At the required time, an aliquot of the reaction mixture was then taken in such a manner as to exclude any clay mineral and slowly added to ethanol with stirring. The precipitated copolymer was filtered off and dried under vacuum, and weighed. Intrinsic viscosity $(\eta)$ measurements were performed at $25^{\circ} \mathrm{C}$ in acetone using a capillary viscometer SEMATECH (VISCOLOGIC TL1). The sample concentration was $1 \mathrm{mg} / \mathrm{ml} .{ }^{1} \mathrm{H}-$ NMR and ${ }^{13} \mathrm{C}$-NMR spectra were recorded on an AM300 FT Bruker instrument using deuterated chloroform as a solvent and tetramethylsilane (TMS) as an internal standard. FT-IR measurements were performed using Alpha -FTIR-Spectrometer BRUKER optics Diamond ATR.

\section{Results and Discussion}

\subsection{Characterization of products.}

The IR spectrum of the copolymer (Figure.1) showed bands due to PSt: bands at 3025 $\mathrm{cm}^{-1}$ (aromatic C-H stretching), at $2970 \mathrm{~cm}^{-1}$ (symmetrical stretching band $-\mathrm{CH}_{2}$ ), at $1599 \mathrm{~cm}$ ${ }^{-1}$ (C-C stretching within the ring) and at 753 and $695 \mathrm{~cm}^{-1}$ (out-of-plane C-H bending vibrations of the monosubstituted aromatic). The spectrum of PPO showed bands at $1096 \mathrm{~cm}^{-1}$ (asymmetrical C-O-C stretching). Similar results are reported elsewhere

$[19$, 34, 37, 39-40]. 


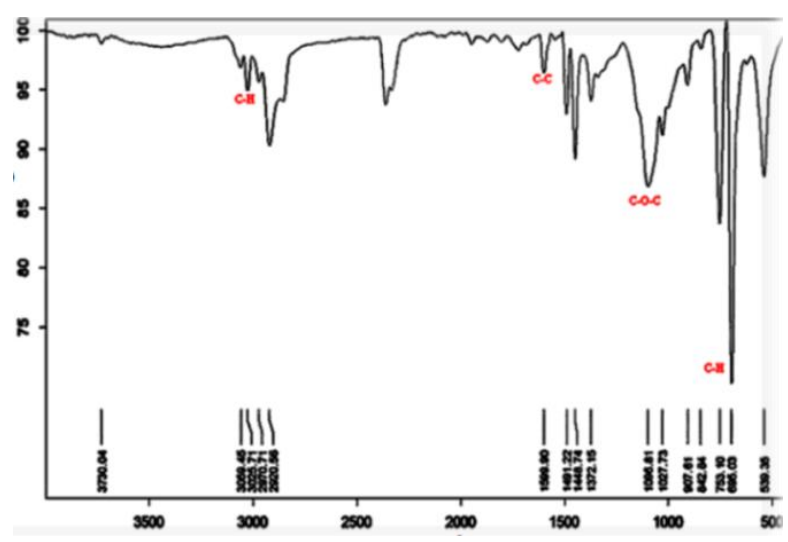

Figure 1. FTIR spectrum of Poly (OP $-\mathrm{co}-\mathrm{St})$.

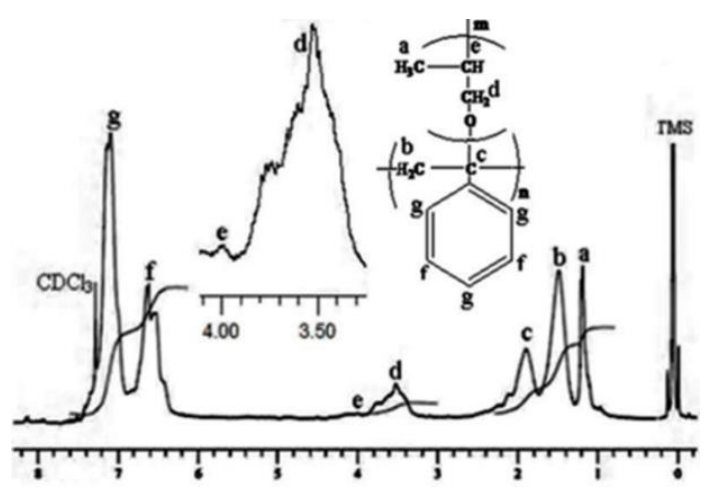

Figure 2. ${ }^{1} \mathrm{H}-\mathrm{NMR}$ spectrum of Poly (OP-co-St).

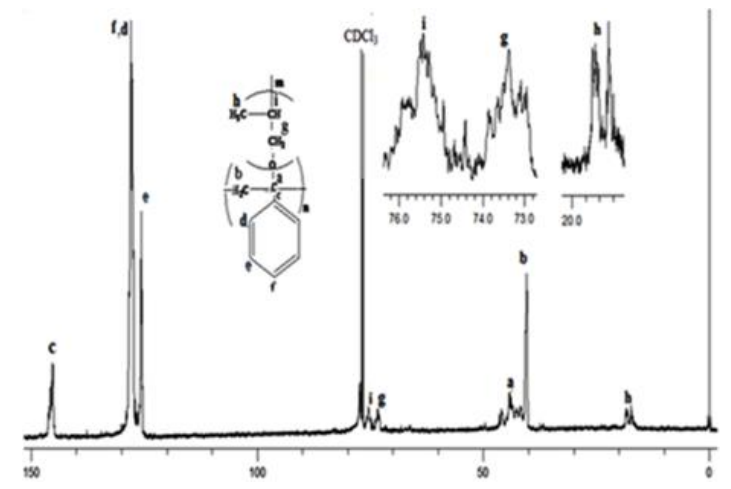

Figure 3. ${ }^{13} \mathrm{C}-\mathrm{NMR}$ spectrum of Poly (OP-co-St).

Figure 2 the ${ }^{1} \mathrm{H}$ NMR $\left(\mathrm{CDCl}_{3}\right)$ spectra show The absorption peaks at 6.60 , and 7.08 ppm (taken together) originating from the aromatic protons of the styrene and those at 1.49 ppm and 1.91ppm for the methylene and methine groups of PSt reveals characteristic resonance lines for the methyl groups of the POP $\left(\mathrm{CH}_{3}\right)$ repeating units at $\delta=1.1 \mathrm{ppm}$ and the absorption at 3.49 and $3.99 \mathrm{ppm}$ due the methylene and methine groups of the POP. [19,41-42].

The ${ }^{13} \mathrm{C}$-NMR $\left(\mathrm{CDCl}_{3}\right)$ spectrum Figure 3 shows the signals for the POP unit at $\delta=$ 16.27-18.05 $\left(\mathrm{CH}_{3}\right), 73.33\left(\mathrm{CH}_{2}\right)$ and $75.48(\mathrm{CH})$ ppm respectively, and others attributed to PSt at [145.35-146, 127.68-128, 125.67 (aromatic carbons of PSt) 40.45, 44.23-46.43 (aliphatic carbons of PSt) ppm. [34,42].

\subsection{Effect of the amount of Mag- $H^{+}$on the copolymerization.}

The effect of the amount of Maghnite- $\mathrm{H}^{+}$on the copolymerization was examined (Table 1). It can be noted that the yield increases with increasing "Maghnite- $\mathrm{H}^{+} 0.25 \mathrm{M}$ proportion. Indeed, using various amounts of $\mathrm{Mag}-\mathrm{H}^{+}, 2.5,5$, and $10 \%$ by weight, the polymerization was 
carried in bulk at $20{ }^{\circ} \mathrm{C}$. The polymerization rate increases with the amount of Mag- $\mathrm{H}^{+}$. In contrast, the intrinsic viscosity $(\eta)$ is inversely proportional to the amount of Mag-H+. The effect of Mag- $\mathrm{H}^{+}$as a catalyst is clearly shown. This phenomenon is probably the result of the number of "initiating active sites" responsible for inducing polymerization; this number is pro rata to the catalyst amount used in the reaction. Belbachir obtains similar results and al [22, 3537] and Njopwouo et al. [38] in the polymerization of N-vinyl pyrrolidone and THF by Mag$\mathrm{H}^{+}$and the polymerization of styrene by montmorillonite, respectively.

Table 1. Copolymerization using different amounts of Maghnite-H+.

\begin{tabular}{|c|c|c|}
\hline $\left.\mathrm{MagH}^{+} \mathbf{0 . 2 5 \%}\right)$ & Yields (\%) & {$[\eta](d l / g)^{a}$} \\
\hline 2,5 & 35,42 & 1,42 \\
\hline 5 & 68,44 & 1,65 \\
\hline 10 & 70,55 & 1,54 \\
\hline
\end{tabular}

$[\mathrm{OP}]=0,083 \mathrm{~mol} ;[\mathrm{St}]=0,083 \mathrm{~mol}$; Reaction time $=8 \mathrm{~h} ; \mathrm{T}=20^{\circ} \mathrm{C}$, a Determined acetone at $25^{\circ} \mathrm{C}$.

\subsection{Effect of the reaction time on the copolymerization.}

Polymerization using $10 \%$ of Maghnite- $\mathrm{H}+0.25 \mathrm{M}$ was carried in bulk at $20{ }^{\circ} \mathrm{C}$, and the reaction was monitored at various times. The results are given in Table 2 , showing the evolution of the yield and the copolymer's intrinsic viscosity with reaction time. The intrinsic viscosity increases with polymerization time. On the other hand, the yield increases with time, and it can be noted that initially, the polymerization proceeds very slowly; this can be considered as an induction period $(6 \mathrm{~h})$. At the end of this period, the polymerization process becomes faster.

Table 2. Kinetic evolution of the copolymerization of OP with styrene en catalyzed by Maghnite-H+ $0.25 \mathrm{M}$.

\begin{tabular}{c|c|c} 
Time(h) & Yield(\%) & {$[\boldsymbol{\eta}](\mathbf{d} \mathbf{l} / \mathbf{g})^{\mathbf{a}}$} \\
\hline 1 & 22,21 & 0,52 \\
3 & 29,53 & 0,65 \\
\hline 5 & 34,91 & 0,76 \\
\hline 6 & 44,65 & 1,13 \\
\hline 7 & 59,56 & 1,32 \\
\hline 8 & 70,55 & 1,54
\end{tabular}

$[\mathrm{OP}]=0,083 \mathrm{~mol} ;[\mathrm{St}]=0,083 \mathrm{~mol} ; 10 \%$ of Maghnite $-\mathrm{H}^{+} 0.25 \mathrm{M} ; \mathrm{T}=20^{\circ} \mathrm{C}$; a Determined acetone at $25{ }^{\circ} \mathrm{C}$.

\section{Conclusions}

In conclusion, it was proved that $\mathrm{Mag}-\mathrm{H}^{+}$could be used to induce the copolymerization of propylene oxide with styrene. A very simple procedure obtained the products via cationic transformation in one step at room temperature. Actually, the efficiency of the copolymerization reflected the Lewis acidity of Maghnite- $\mathrm{H}^{+}$. Two main advantages were shown in the copolymerization system using solid acid Maghnite- $\mathrm{H}^{+}$. The catalyst could be removed from the mixture of the products by simple filtration and recycled without a loss of catalytic activity. ${ }^{1} \mathrm{H}-\mathrm{NMR},{ }^{13} \mathrm{C}-\mathrm{NMR}$, and IR confirmed the structure of copolymers.

\section{Funding}

This research received no external funding.

\section{Acknowledgments}

We thank all laboratory staff of polymer chemistry from the University of Oran 1 for their kind cooperation. 


\section{Conflicts of Interest}

\section{The authors declare no conflict of interest.}

\section{References}

1. Owens, K.; Kyllingstad, V. Remarkable Room-Temperature Insertion of Carbon Monoxide in to an Aluminum-Carbon Bond of Tri-tert-butylaluminum. Kirk - Othmer Encyclopedia of Chemical Technology, 4th, Edition, Wiley 1993, 8, 1079-1093.

2. Jr Bailey, F.E.; Koleske, J.V. Alkylene Oxides and Their Polymers. Surfactant Science Series 35,Marcel Dekker, New York, Chapter 4. Journal of Dispersion Science and Technology 1991, 13, 247-248, https://doi.org/10.1080/01932699208943312.

3. Sârbu, T.; Beckman, E.J. Homopolymerization and Copolymerization of Cyclohexene Oxide with Carbon Dioxide Using Zinc and Aluminum Catalysts. Macromolecules 1999, 32, 6904-6912, https://doi.org/10.1021/ma990463t.

4. Aida, T.; Inoue, S. Metalloporphyrins as Initiators for Living and Immortal Polymerizations. Accounts of Chemical Research 1996, 29, 39-48, https://doi.org/10.1021/ar9500291.

5. Rabagliati, F.M.; Contreras, J.M. Epoxy polymerization-IX. Styrene oxide polymerization using the diphenylzinc-water system in benzene at various temperatures. European Polymer Journal 1987, 23, 63-67, https://doi.org/10.1016/0014-3057(87)90099-1.

6. Emig, N.; Nguyen, H.; Krautscheid, H.; Réau, R.; Cazaux, J.-B.; Bertrand, G. Neutral and Cationic Tetracoordinated Aluminum Complexes Featuring Tridentate Nitrogen Donors: Synthesis, Structure, and Catalytic Activity for the Ring-Opening Polymerization of Propylene Oxide and (d,1)-Lactide. Organometallics 1998, 17, 3599-3608, https://doi.org/10.1021/om980401b.

7. Chisholm, M.H.; Crandall, J.K.; McCollum, D.G.; Pagel, M. Concerning the Mechanism of Ring-Opening Polymerization by Coordinate Catalysts: The 2D Homonuclear J-Resolved Spectrum of Poly(cyclohexene oxide). Macromolecules 1999, 32, 5744-5746, https://doi.org/10.1021/ma9901745.

8. Kobayashi, S.; Kaku, M.; Mizutani, T.; Saegusa, T. Preparation of ring-opening polymerizable macromer and its copolymerization leading to graft copolymer. Polymer Bulletin 1983, 9, 169-173, https://doi.org/10.1007/BF00283702.

9. Tsukahara, Y.; Ito, K.; Tsai, H., Yamashita, Y. Water-soluble graft copolymers from macromonomer method. J Polym, Sci Chem, Edn 1989, 27, 1099-1114.

10. Percec, V.; Wang, J.H.J.M.S. The synthesis and reactivity of é (p vinylbenzyl ether) macromonomer of poly(2,6 dimethyl 1,T phenylene ether). Makromolec. Chem. Macromolec. Syrup 1992, 54, 561-581.

11. Gnanou, Y.; Lutz, P. The ability of macromonomers to copolymerize: A critical review with new developments. Die Makromolekulare Chemie 1989, 190, 577-588.

12. Oliveira, C.M.F.; Lucas, E.F. Graft copolymers of poly(methyl methacrylate) backbone and poly(propylene oxide-b-ethylene oxide) branches. Polymer Bulletin 1990, 24, 363-370, https://doi.org/10.1007/BF00294088.

13. Amorim, M.C.V.; Oliveira, C.M.F. Poly(methyl methacrylate)-graft-[poly(ethylene oxide); poly(propylene oxide)]-1. Synthesis and characterization. European Polymer Journal 1992, 28, 449-452, https://doi.org/10.1016/0014-3057(92)90117-K.

14. Wicker, M.; Heitz,W.Copolymerization of macromonomers of poly(2,6 dimethyl 1,4-phenylene oxide) with various comonomers. Makromolec. Chem 1991, 192, 1371-1385.

15. Cameron, G.G.; Chisholm, M.S. Polymerization of poly(dimethylsiloxane) macromers: 2. Glass transition temperatures of macromer/styrene copolymers. Polymer 1986, 27, 437-440, https://doi.org/10.1016/00323861(86)90162-X.

16. Masuda, E.; Kishiro, S.; Kitayama, T.; Hatada, K. Radical Polymerization of Highly Isotactic and Syndiotactic Poly(methyl methacrylate) Macromonomers. Polymer Journal 1991, 23, 847-857, https://doi.org/10.1295/polymj.23.847.

17. Shoda, S.-I.; Masuda, E.; Furukawa, M.; Kobayashi, S. Synthesis and surfactant property of copolymers having a poly(2-oxazoline) graft chain. Journal of Polymer Science Part A: Polymer Chemistry 1992, 30, 1489-1494.

18. Ito, K.; Tsuchida, H.; Hayashi, A.; Kitano, T.; Yamada, E.; Matsumoto, T. Reactivity of Poly(ethylene oxide) Macromonomers in Radical Copolymerization. Polymer Journal 1985, 17, 827-839, https://doi.org/10.1295/polymj.17.827.

19. Cunha, H.T.; Oliveira, C.M.F. Copolymerization of poly(propylene oxide) methacrylate macromonomer with styrene. European Polymer Journal 1994, 30, 1489-1491.

20. Ferrahi, M.I.; Belbachir, M. Preparation of Poly(oxybutyleneoxymaleoyl) Catalyzed by a Proton Exchanged Montmorillonite Clay. Molecules 2004, 9, https://doi.org/10.3390/91100968.

21. Malika, A.; Amine, H.; Mohammed, B. Polymerization of $\beta$-pinene by using natural montmorillonite clay as a green catalyst. Green Mater 2018, 6, 58-64, https://doi.org/10.1680/jgrma.17.00040. 
22. Seghier, S.; Belbachir, M. Degradation of Poly(3-(Oxiran-2-ylmethyl) Oxazolidin-2-one) in the Presence of an Algerian Activated Clay. Iranian Journal of Science and Technology, Transactions A: Science 2019, 43, 1545-1550, https://doi.org/10.1007/s40995-018-0629-2.

23. Song, Q.; Zhao, J.; Zhang, G.; Taton, D.; Peruch, F.; Carlotti, S. N-Heterocyclic carbene/Lewis acidmediated ring-opening polymerization of propylene oxide. Part 2: Toward dihydroxytelechelic polyethers using triethylborane. $\quad$ European $\quad$ Polymer $\quad$ Journal https://doi.org/10.1016/j.eurpolymj.2020.109839.

24. Pappuru, S.; Chakraborty, D. Progress in metal-free cooperative catalysis for the ring-opening copolymerization of cyclic anhydrides and epoxides. European Polymer Journal 2019, 121, https://doi.org/10.1016/j.Eurpolymj.2019.109276.

25. Haoue, S.; Derdar, H.; Belbachir, M.; Harrane, A. Polymerization of Ethylene Glycol Dimethacrylate (EGDM), Using An Algerian Clay as Eco-catalyst (Maghnite-H+ and Maghnite-Na+). Bulletin of Chemical Reaction Engineering \& Catalysis 2020, 15, 221-230, https://doi.org/10.9767/bcrec.15.1.6297.221-230.

26. Embarek, N.; Nabahat, S. A Novel Green Synthesis Method of Poly (3-GlycidoxypropylTrimethoxysilane) Catalyzed by Treated Bentonite. Bulletin of Chemical Reaction Engineering \& Catalysis 2020, 15, 290-303, https://doi.org/10.9767/bcrec.15.2.6568.290-303.

27. Derdar, H.; Belbachir, M.; Hennaoui, F.; Akeb, M.; Harrane, A. Green Copolymerization of Limonene with $\beta$-Pinene Catalyzed by an Eco-Catalyst Maghnite-H+. Polymer Science, Series B 2018, 60, 555-562, https://doi.org/10.1134/S1560090418050056.

28. Derkaoui, S.; Belbachir, M.; Haoue, S.; Zeggai, F.Z.; Rahmouni, A.; Ayat, M. Homopolymerization of methacrylamide by anionic process under effect of Maghnite-Na+ (Algerian MMT). Journal of Organometallic Chemistry 2019, 893, 52-60, https://doi.org/10.1016/j.jorganchem.2019.04.024.

29. Van Schijndel, J.; Molendijk, D.; van Beurden, K.; Canalle, L.A.; Noël, T.; Meuldijk, J. Preparation of biobased styrene alternatives and their free radical polymerization. European Polymer Journal 2020, 125, https://doi.org/10.1016/j.eurpolymj.2020.109534.

30. Ji, H.-Y.; Song, D.-P.; Wang, B.; Pan, L.; Li, Y.-S. Organic Lewis pairs for selective copolymerization of epoxides with anhydrides to access sequence-controlled block copolymers. Green Chemistry 2019, 21, 61236132, https://doi.org/10.1039/C9GC02429H.

31. Chen, Y.; Liu, S.; Zhao, J.; Pahovnik, D.; Žagar, E.; Zhang, G. Chemoselective Polymerization of Epoxides from Carboxylic Acids: Direct Access to Esterified Polyethers and Biodegradable Polyurethanes. ACS Macro Letters 2019, 8, 1582-1587, https://doi.org/10.1021/acsmacrolett.9b00789.

32. Shi, J.; Shi, Z.; Yan, H.; Wang, X.; Zhang, X.; Lin, Q.; Zhu, L. Synthesis of Zn-Fe double metal cyanide complexes with imidazolium-based ionic liquid cocatalysts via ball milling for copolymerization of $\mathrm{CO} 2$ and propylene oxide. RSC Advances 2018, 8, 6565-6571, https://doi.org/10.1039/C7RA12528C.

33. Tran, C.H.; Pham, L.T.T.; Lee, Y.; Jang, H.B.; Kim, S.; Kim, I. Mechanistic insights on Zn(II)-Co(III) double metal cyanide-catalyzed ring-opening polymerization of epoxides. J. Catal. 2019, 372, 86-102, https://doi.org/10.1016/j.jcat.2019.02.028.

34. Cherifi, Z.; Boukoussa, B.; Zaoui, A.; Belbachir, M.; Meghabar, R. Structural, morphological and thermal properties of nanocomposites poly(GMA)/clay prepared by ultrasound and in-situ polymerization. Ultrasonics Sonochemistry 2018, 48, 188-198, https://doi.org/10.1016/j.ultsonch.2018.05.027.

35. Derdar, H.; Belbachir, M.; Harrane, A. A Green Synthesis of Polylimonene Using Mag-H+, an Exchanged Montmorillonite Clay, as Eco-Catalyst. Bulletin of Chemical Reaction Engineering \& Catalysis 2019, 14, 69-78, https://doi.org/10.9767/bcrec.14.1.2692.69-78.

36. Wieland, H.; Helmut, K.; Hartwig, H. Tetraphenylporphyrin aluminium compounds as initiators for the ringopening polymerization of 2, 2 dimethyltrimethylene carbonate: synthesis of homopolymers and copolymers with E-caprolactone, ethylene oxide and propylene oxide. Polymer 1992, 33, 1941-1948.

37. 32.Bouchama, A.; Ferrahi,M.I.;Belbachir,M. Synthesis of poly ( $\varepsilon$-caprolactone-co-propylene oxide) by a green catalyst, Maghnite. Global Journal of Science Frontier Research Chemistry 2012, 12, 1-4.

38. Njopwouo, D.; Roques, G.; Wandji, R. A contribution to the study of the catalytic action of clays on the polymerization of styrene: I. Characterization of polystyrenes. Clay Minerals 1987, 22, 145-156, https://doi.org/10.1180/claymin.1987.022.2.03.

39. Grobelny, Z.; Matlengiewicz, M.; Jurek-Suliga, J.; Golba, S.; Skrzeczyna, K. The influence of initiator and macrocyclic ligand on unsaturation and molar mass of poly(propylene oxide)s prepared with various anionic system. Polymer Bulletin 2018, 75, 1101-1121, https://doi.org/10.1007/s00289-017-2078-z.

40. Abdollahi, A.; Roghani-Mamaqani, H.; Salami-Kalajahi, M. Morphology evolution of functionalized styrene and methyl methacrylate copolymer latex nanoparticles by one-step emulsifier-free emulsion polymerization. European Polymer Journal 2020, 133, https://doi.org/10.1016/j.eurpolymj.2020.109790.

41. Simula, A.; Ballard, N.; Aguirre, M.; Leiza, J.R.; Es, S.V.; Asua, J.M. Nitroxide mediated copolymerization of acrylates, methacrylates and styrene: The importance of side reactions in the polymerization of acrylates. European Polymer Journal 2019, 110, 319-329, https://doi.org/10.1016/j.eurpolymj.2018.11.041.

42. Hassanabadi, M.; Najafi, M.; Hashemi Motlagh, G.; Saeedi Garakani, S. Synthesis and characterization of end-functionalized solution polymerized styrene-butadiene rubber and study the impact of silica dispersion 
improvement on the wear behavior of the composite. Polymer Testing 2020, 85, https://doi.org/10.1016/j.polymertesting.2020.106431. 